\title{
Long-term copper mine waste disposal in northern Chile associated with gene flow disruption of the intertidal kelp Lessonia nigrescens
}

\author{
Sylvain Faugeron ${ }^{1}$, Enrique A. Martínez ${ }^{1,2}$, Juan A. Correa ${ }^{1, *}$, Claire Billot $^{3}$ \\ ${ }^{1}$ Departamento de Ecología and Center for Advanced Studies in Ecology and Biodiversity, Facultad de Ciencias Biológicas, \\ Pontificia Universidad Católica de Chile, Alameda 340, Santiago, Chile \\ ${ }^{2}$ Centre de Coopération International en Recherche Agronomique pour le Développement, \\ UMR Polymorphismes d'Intéret Agronomique, Avenue d'Agropolis, 34398 Montpellier Cedex 05, France \\ ${ }^{3}$ Present address: Centro de Estudios Avanzados en Zonas Aridas, Universidad de La Serena, Benavente 980, \\ La Serena, Chile
}

\begin{abstract}
This study tests the general hypothesis that habitat disruption caused by the release of copper mine wastes in coastal waters has a negative impact on gene flow among populations of the kelp Lessonia nigrescens Bory. Hierarchical sampling was performed within continuous, undisturbed stands and at the northern and southern edges of a $40 \mathrm{~km}$ gap caused by mine wastes. Our results, based on RAPD markers, showed a strong genetic structure even in the absence of the disrupting effect of the mine wastes. No pattern of isolation by distance is apparent, however, which indicates that populations are at migration-drift disequilibrium, and suggests that most events of spore recruitment and/or gametophyte fertilization occur within a few metres. On the other hand, some long distance dispersal is likely to occur, which prevents isolation by distance within the spatial scale of $40 \mathrm{~km}$. When comparing continuous stands across the disrupted habitat, an increased genetic differentiation associated with the interruption of the species distribution was observed. A Multiple Correspondence Analysis (MCA) clearly separated the sampling units into 2 groups, each representing a separate stand. Other lines of evidence supporting the idea of genetic disruption came from the mean pairwise differentiation estimates $\left(F_{\mathrm{ST}}\right)$ and from the Analyses of Molecular Variance (AMOVA). Finally, the southern edge of the interruption in the distribution of L. nigrescens showed clear signals of a recent founding event, suggesting that northward recolonisation is currently occurring.
\end{abstract}

KEY WORDS: Kelp $\cdot$ Habitat disruption $\cdot$ Heavy metal $\cdot$ Gene flow $\cdot$ RAPD

\section{INTRODUCTION}

Habitat fragmentation, through the isolation and size reduction of originally continuous populations, is a major threat to any species as it reduces population viability by affecting population dynamics and genetic diversity (i.e. Saunders et al. 1991, Young et al. 1996). The metapopulation theory has been widely used to predict the effects of habitat fragmentation (Hanski \& Gilpin 1997). It is not clear, however, what the magnitude of such a pertubation that would cause the disruption of a given population is (Caizergues et al. 2003,
Murren 2003), and therefore, inferring the effects of habitat fragmentation among natural populations may prove to be a difficult task (Williams et al. 2003). Part of this problem stems from the fact that the distribution of a species is often naturally discontinuous, due to the heterogeneity of the environment and the discontinuities of a habitat. Even in the marine environment, often considered a priori as a continuous habitat that favors dispersion, discontinuities are frequently present and, sometimes, result in clear interruptions of the species distribution or act as barriers to migration among populations (Palumbi 1994, Riginos \& Nachman 
2001). Furthermore, there is increasing evidence that these habitat discontinuities represent a key factor in reducing gene flow among marine populations and, thus, favours genetic differentiation. Examples include rock-reef fishes, where sandy beaches or deeper waters among islands can inhibit gene flow even in the presence of tidal currents (Bernardi 2000, Riginos \& Nachman 2001), intertidal snails (Johnson \& Black 1995) and other animal populations (reviewed by Palumbi 1994, Bohonak 1999). In seaweeds, accumulating evidence shows that, in most cases, gene flow occurs mainly between populations separated by short distances as a result of their short dispersal capacity (Valero et al. 2001). As a consequence, any interruption in their distribution is expected to accelerate genetic differentiation. For example, it was shown that natural discontinuities of the coast, such as estuaries and sandy beaches, strongly increases population differentiation at spatial scales of $5 \mathrm{~km}$ in the rocky intertidal red alga Mazzaella laminarioides (Faugeron et al. 2001, Faugeron 2002). Similar responses were reported for the brown alga Laminaria digitata, where relatively short interruptions (15 to $20 \mathrm{~km}$ ) in its usually continuous distribution increases genetic differentiation (Billot et al. 2003). At a local spatial scale, spatial and temporal heterogeneity has been associated with a reduced and/or asymmetrical gene flow (Engel et al. 2004) and strong genetic and physiological substructuring of the populations (Ruckelshaus 1998, Wright et al. 2000, Zucarello et al. 2001).

Whenever sensitivity to habitat discontinuities has been assessed using organisms with low dispersal capacities, it has become a major challenge to separate the effects of natural discontinuities and the resulting historical barriers to gene flow from contemporary processes such as habitat fragmentation induced by humans (Young et al. 1996, Sork et al. 1999, Manel et al. 2003, Williams et al. 2003). Furthermore, contemporary changes in the pattern of gene flow may have no effect on the current genetic structure because genetic drift requires several generations to alter allele frequencies within populations. In this context, long generation times, large population sizes, or both are expected to cause the genetic structure of a population to remain unchanged for long periods of time, and make the detection of possible effects of human-induced population fragmentation difficult. Therefore, in order to properly sort past from contempory factors shaping a population, studies assessing the effects of habitat fragmentation on genetic structure must include sampling at similar spatial scales in both fragmented and continuous habitats (i.e. Caizergues et al. 2003, Williams et al. 2003).

Taking all the above into consideration, the present study assesses the potential effects of a human-induced barrier to gene flow on the genetic differentia- tion among kelp populations in northern Chile. Among the anthropogenic activities known to have caused severe and persistent disruptions in local diversity and abundance of intertidal and subtidal communities in northern Chile are those resulting from the disposal of solid and liquid wastes from copper mining. At 1 of these sites, Chañaral Bay, since the mining operations began in the early 1940s, major beach progradation, caused by the accumulation of sediments with high copper content, was accompanied by the disappearance of entire assemblages of benthic organisms around the discharge points. After more than $60 \mathrm{yr}$ of continuous waste discharges, Chañaral Bay is currently characterized by the presence of artificial tailing beaches interrupting the rocky coastline for $25 \mathrm{~km}$, and a chronic enrichment of the coastal water by heavy metals, mainly copper (Correa et al. 1999). These changes in habitat were accompanied by an overall reduction in biological diversity and the persistent occurrence of intertidal benthic communities with a simplified structure (Castilla \& Nealler 1978, Correa et al. 1999). An important kelp which is absent from this impacted area is Lessonia nigrescens Bory, one of the most ecologically and economically important species in the rocky intertidal habitats of the western southern Pacific (Santelices et al. 1980, Santelices \& Ojeda 1984, Vásquez et al. 1998). Its ecological importance as an engineer species (sensu Jones et al. 1994) is suggested by studies showing that $L$. nigrescens facilitates the recruitment of macro-invertebrates and algae that find refuge from desiccation and wave impact (Villouta \& Santelices 1984). The importance of this species is further supported by reports demonstrating the role of the holdfast as a habitat for several taxa of intertidal invertebrates (Cancino \& Santelices 1984, Vásquez \& Santelices 1984, Muñoz \& Santelices 1989). L. nigrescens is also a main marine commercial resource for the production of alginates, gel-forming polysaccharides, included in food, cosmetics and paint industries. L. nigrescens, a species with an apparently poor capacity for dispersal, has a heteromorphic haploid-diploid life cycle, with a macroscopic diploid phase (the sporophyte), and a microscopic haploid phase (the gametophyte). Despite the dispersal capacity of the meiospores released by the sporophytic thallus, the occurrence of an obligate alternate gametophytic phase, with separate male and female individuals, makes the dispersal of the species more complex and a successful recruitment of the sporophytic phase more difficult. For this reason, recovery of the continuity in L. nigrescens populations following natural or anthropic habitat disruptions is expected to be slow, as recently reported for re-colonization patterns after massive mortality of this kelp associated with the El Niño climatic event in 1982 (Martínez et al. 2003). 


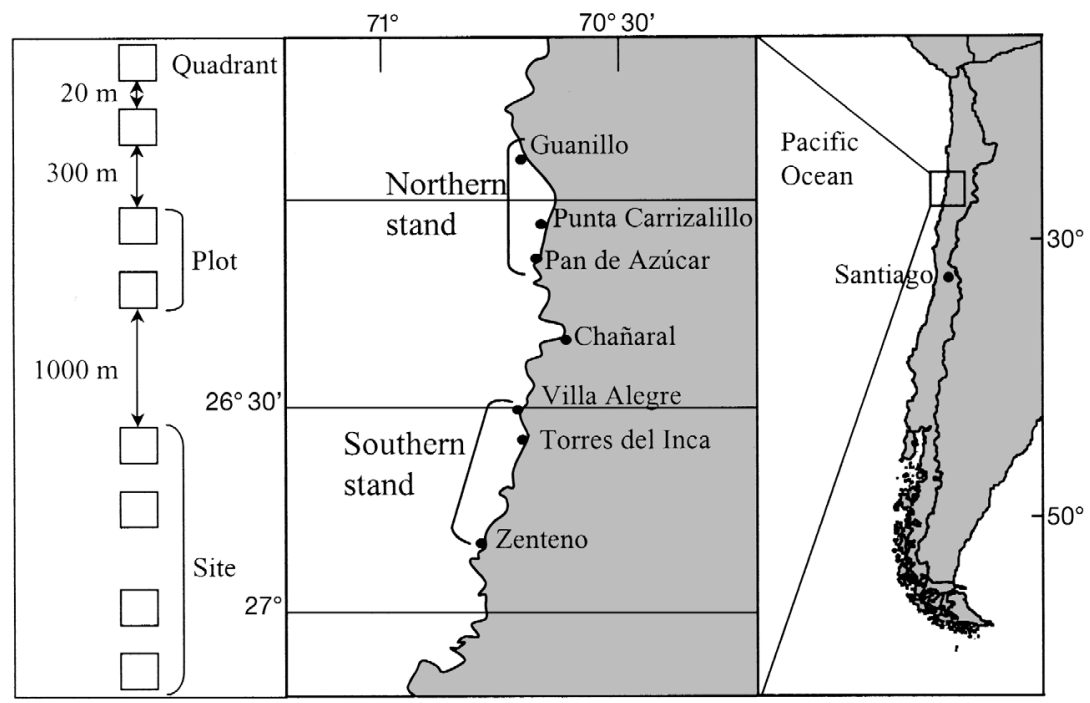

Fig. 1. Study sites and hierarchical sampling design applied within each sampled locality. The coastal area directy impacted by the mine wastes, where Lessonia nigerscens is totally absent, stretches northward from Villa Alegre to Pan de Azúcar

This study was designed to test the general hypothesis that genetic structure and gene flow in populations of Lessonia nigrescens were negatively affected by the disruption of its habitat resulting from more than $60 \mathrm{yr}$ of continuous mining wastes disposal. We used RAPD markers to characterize population genetic structure within and between continuous stands separated by the impacted area.

\section{MATERIALS AND METHODS}

Sampling design. The coast around the city of Chañaral was systematically screened to determine the exact points where the continuous distribution of the southern and northern stands of Lessonia nigrescens were interrupted. A hierarchical sampling design (Fig. 1) was applied in the northern and southern stands to incorporate different geographical distances, with 3 localities sampled in each stand. The 2 localities at the very border of the disruption were Pan de Azúcar in the northern stand and Villa Alegre in the southern stand, both separated by $42 \mathrm{~km}$ (linear distance). In each stand, 1 locality was chosen at a distance from the border similar to the disruption distance. In the northern stand, Guanillo was located at $35 \mathrm{~km}$ from Pan de Azúcar, and in the southern stand, Zenteno was chosen at $40 \mathrm{~km}$ from Villa Alegre. Finally, 2 localities were chosen close $(10 \mathrm{~km})$ to the border sites, i.e. Punta Carrizalillo for the northern stand and Torres del Inca for the southern stand. The sampling scheme included quadrants of $5 \mathrm{~m}^{2}$ as the basic sampling unit, plots made of 2 quadrants separated by $20 \mathrm{~m}$ and sites made of 2 plots separated by $300 \mathrm{~m}$. Each locality included 2 sites separated by $1 \mathrm{~km}$. The density of individuals was recorded at each site using transects and by counting all individuals in $1 \mathrm{~m}^{2}$ quadrants separated $5 \mathrm{~m}$ from each other. Within each quadrant, 30 to 35 individuals were sampled for molecular analysis.

Tissue preparation, DNA extraction and RAPD-PCR. Each sampled frond was brushed under running tap water and carefully checked for the absence of epiphytes, necrosis, reproductive sori or any other feature indicative of contamination or tissue degradation. Thin flakes of cortical tissue were excised from clean and healthy parts of the fronds and put in $2 \mathrm{ml}$ tubes with silica gel beads. DNA was extracted from $3 \times 3 \mathrm{~mm}$ fragments of cortical tissue following the protocol of Martínez et al. (2003), with the exception that the tissue was directly ground in the $2 \mathrm{ml}$ tubes with the extraction buffer using sterile plastic pestles. The quality and quantity of DNA was monitored by electrophoresis on agarose gel and UV absorption at 260 and $280 \mathrm{~nm}$ using a SmartSpec spectrophotometer (Bio-Rad). All the samples were diluted to $10 \mathrm{ng}^{-1}$ and RAPD-PCRs were performed using the same protocol and the same primers described in Martínez et al. (2003). Amplified fragments were separated by electrophoresis on $1.5 \%$ Trisacetic acid-EDTA (TAE) agarose gels stained with ethyl bromide (EtBr) for visualisation. Bands were scored manually from printed pictures and cross checked by 2 people. PCRs were repeated and a total of 33 reproducible and clearly recognizable bands were selected (Table 1). Only samples that produced a clear pattern of presence or absence of the selected RAPD fragments were retained for the subsequent

Table 1. Sequences of RAPD primers used, number and size of the 33 informative bands

\begin{tabular}{|lll|}
\hline $\begin{array}{l}\text { RAPD } \\
\text { primers }\end{array}$ & Sequence $\left(5^{\prime} \rightarrow 3^{\prime}\right)$ & \multicolumn{1}{c|}{ Band sizes (bp) } \\
\hline C2 $(10)$ & GTGAGGCGTC & $1026,885,813,763,672,604,567,458,421,379$ \\
C8 $(8)$ & TGGACCGGTG & $1193,1109,982,936,620,452,431$ \\
C11 (9) & AAAGCTGCGG & $1451,1281,1204,1062,895,745,659,607,465$ \\
L5 $(7)$ & ACGCAGGCAC & $765,733,674,594,557,501,350$ \\
\hline
\end{tabular}


population analyses. Therefore, from a total of about 1000 analyzed samples, 864 were available for data analyses (i.e. 426 individuals from the northern stand and 438 from the southern stand). Mean number of samples per quadrants ranged between 15 in Punta Carrizalillo to 22 in Pan de Azúcar (Fig. 2A). Each band was considered as a phenotypic trait coded as present or absent and assumed to correspond to a single locus.

Data analysis. Kelp density within each stand was compared between border localities and the others by Student's $t$-tests. Genetic diversity within each quadrant was estimated by the percentage of polymorphic loci and the Shannon-Wiener diversity index $\left(H^{\prime}\right.$, Bussell 1999). The average genetic diversity was compared between border localities and the others by Student's $t$-tests. Comparisons were also performed between the northern and southern localities. Additionally, the proportions of phenotypes shared among the individuals of the same locality, among individuals from separate localities and among individuals from the northern and the southern stands were calculated. For the 'between localities' calculations, only 3 combinations were considered, corresponding to pairs of localities separated by equivalent geographic distances: Pan de Azúcar and Villa Alegre (i.e. the area of the disruption), Guanillo and Pan de Azúcar (both from the northern stand) and Villa Alegre and Zenteno (both from the southern stand).

In order to explore the role of the disruption on the distribution pattern of the genetic variance among the northern and southern stands, a Multiple Correspondence Analysis (MCA) was performed using each locus as an independent binary variable. MCA is a simple ordination method based on the principles of factorial analysis of correspondences which has been adapted for multilocus genotypic data (She et al. 1987). It allows a description of the distribution of the genetic diversity within the landscape based on the comparison of the factor map with the geographical map. Furthermore, Guinand (1996) demonstrated the relation of some model parameters with a linear combination of monolocus sub-structure estimates $\left(F_{\mathrm{ST}}\right)$. Because of the high number of individuals involved in the analysis, the output of the MCA was simplified by plotting the center of gravity of groups of individuals defined at the spatial scale of choice, as proposed by the software Genetix (Belkir et al. 1996). This analysis is not strictly equivalent to the Constant Row MCA proposed by Guinand (1996), however, as groups contribute to the total inertia with different weights according to their size. In the present analysis, plots were considered as the basic units. The significance of the genetic differentiation due to the disruption was then estimated by comparing the mean pairwise $F_{\mathrm{ST}}$ among quadrants of the different localities within and between the north-
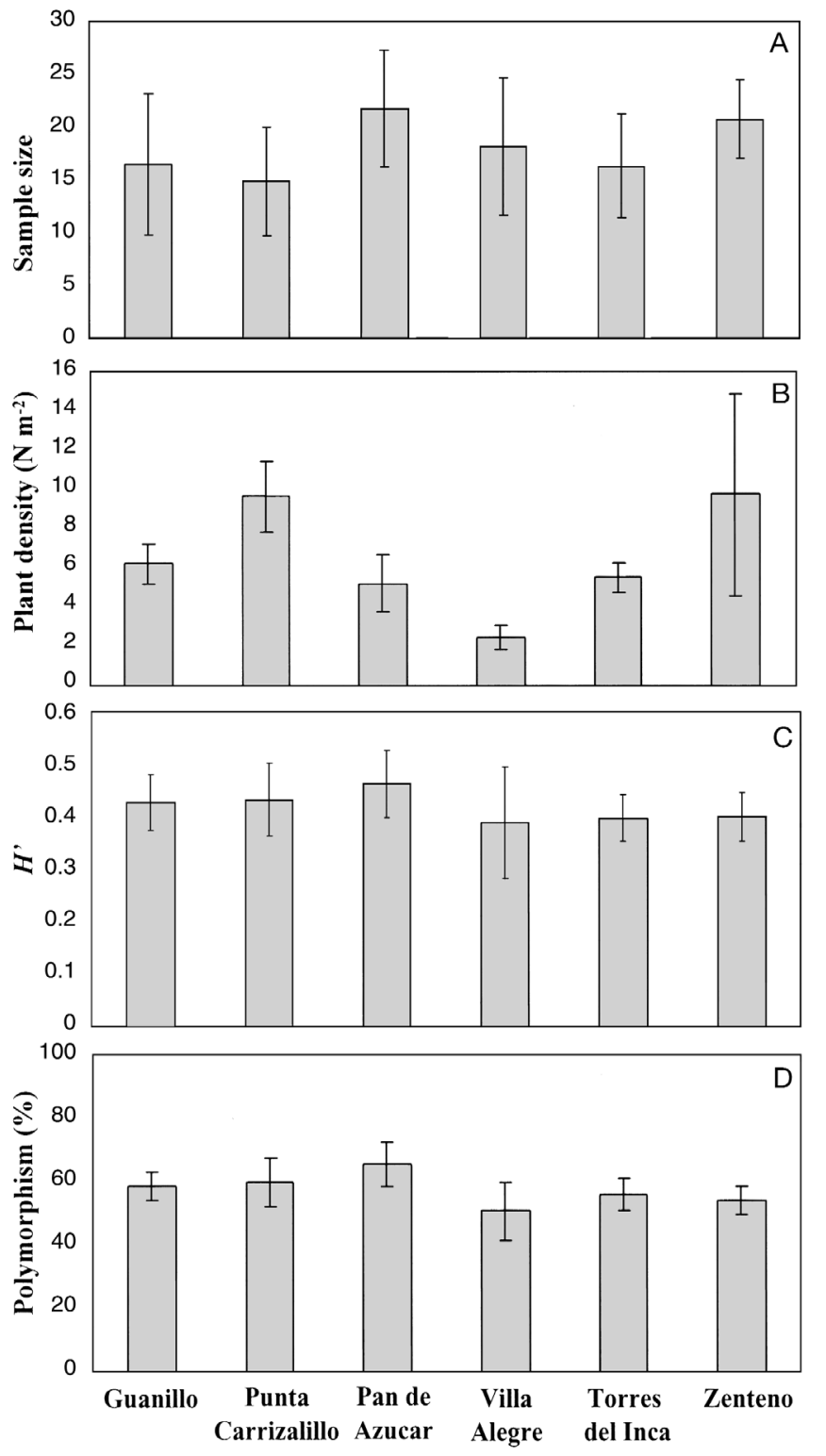

Fig. 2. Average parameter values for populations of Lessonia nigrescens. (A) Mean number of samples analysed per quadrant. (B) Mean density of individuals $\left(\mathrm{N} \mathrm{m}^{-2}\right)$. (C) Mean diversity per quadrant (expressed by the Shannon-Wiener index, $H^{\prime}$ ). (D) Mean percentage of polymorphic loci within quadrants. Bars indicate standard deviation

ern and southern stands. Because of the dominance of the RAPD marker, allele frequencies cannot be estimated properly for diploid organisms. Thus, $F_{\mathrm{ST}}$ values were estimated from the mean number of pairwise differences among phenotypes, that is $\theta(\pi)$, in the Arlequin output (Schneider et al. 2000), a method that does not rely on allele frequencies. The significance of each $F_{\mathrm{ST}}$ estimate was assessed by a permutation test (1000 permutations) followed by sequential Bonferroni's correction when performing multiple tests (Rice 1990). 
Three series of tests were performed in order to assess specific hypotheses regarding the effect of habitat disruption on the population genetic structure of Lessonia nigrescens. The first hypothesis states that, at similar spatial distances, genetic differentiation is greater across the disruption than within each stand (i.e. continuous distribution). It was tested by comparing mean pairwise $F_{\mathrm{ST}}$ between localities between stands (Pan de Azúcar and Villa Alegre, Punta Carrizalillo and Torres del Inca) to mean pairwise $F_{\mathrm{ST}}$ between localities within stands (Zenteno and Villa Alegre, Zenteno and Torres del Inca, Guanillo and Pan de Azúcar, Guanillo and Punta Carrizalillo). The second hypothesis states that genetic differentiation between stands is higher when geographic distance between populations is higher. It was tested by comparing mean pairwise $F_{\mathrm{ST}}$ between pairs of equidistant localities (i.e. Guanillo and Zenteno, Punta Carrizalillo and Torres del Inca, Pan de Azúcar and Villa Allegre). Finally, the third hypothesis states that populations at the border of the habitat disruption are at a migrationdrift disequilibrium. It was tested by comparing mean pairwise $F_{\mathrm{ST}}$ between localities within stands. All comparisons were done using Student's $t$-tests. Three kinds of hierarchical Analyses of Molecular Variances (AMOVA) (Excoffier et al. 1992) were performed to identify the spatial scales at which genetic differentiation occurs: (1) partitioning the total variance into 'Between Stands' and 'Among Localities within Stands', (2) partitioning the total variance within each stand into 'Among Localities' and 'Between Sites within Localities', and (3) partitioning the total variance within each locality into 'Between Sites' and 'Between Plots within Sites'. The different fixation indices were tested by 1000 permutations as follows: global sub-structure index $\left(\Phi_{\mathrm{ST}}\right)$ was tested by permuting phenotypes among sub-groups among groups; differentiation between sub-groups within groups $\left(\Phi_{\mathrm{SC}}\right)$ was tested by permuting phenotypes among subgroups within groups; and differentiation between groups $\left(\Phi_{\mathrm{CT}}\right)$ was tested by permuting sub-groups among groups.

\section{RESULTS}

Overall, mean density of Lessonia nigrescens for the localities under study was of 5.9 individuals $\mathrm{m}^{-2}$ $(\mathrm{SD}=5.4)$. It was slightly but significantly higher in the northern than in the southern stand $(t=2.55$, $\mathrm{p}=0.014$ ). In addition, density of adult plants was significantly lower at the 2 border localities $(t=8.75$, $\mathrm{p}<0.0001$; Fig. 2B), particularly at Villa Alegre, when compared with all the other localities. Whereas in the southern-most locality of Zenteno the mean density was significantly higher than at the northern-most locality, Guanillo ( $t=2.93$, p $<0.0027)$, an important intra-locality patchiness was apparent as indicated by its higher variance (Fig. 2B).

The 2 indices of genetic diversity, Shannon-Wiener index and polymorphism (\% of polymorphic loci), were significantly higher the 3 localities from the northern stand than the 3 from the southern stand (Fig. 2C; $t=2.643, \mathrm{p}<0.05, t$-test on transformed values to satisfy normality requirements). Overall, polymorphism was high $(93.9 \%)$, with the lowest values observed in samples from Villa Alegre (Fig. 2D). In general, at the smallest spatial scale, 30 out of the 48 quadrants had 20 or more polymorphic loci (out of 33 loci), and only 2 cases had less than 15 polymorphic loci (data not shown). Comparisons between the border sites and the others did not show significant differences.

The first factorial axis of the MCA explained ca. $25.3 \%$ of the total variance and clearly separated the individuals, represented by the center of gravity of the plots, into a northern group with positive coordinates and a southern group with negative coordinates (Fig. 3). In addition, the edge plot in Pan de Azúcar (i.e. the closest to the disruption area) had the highest positive coordinate on this axis, whereas the second plot of Villa Alegre (at $300 \mathrm{~m}$ of the edge plot) had the highest negative coordinate. The second factorial axis explained $18.1 \%$ of the total variance and separated the border, northern-most plot from Villa Alegre, from all the others (Fig. 3). Except for plots from Torres del Inca, which tightly grouped on the first axis, all other plots appeared dispersed and intermixed with those from the same stand, indicating that the geographic

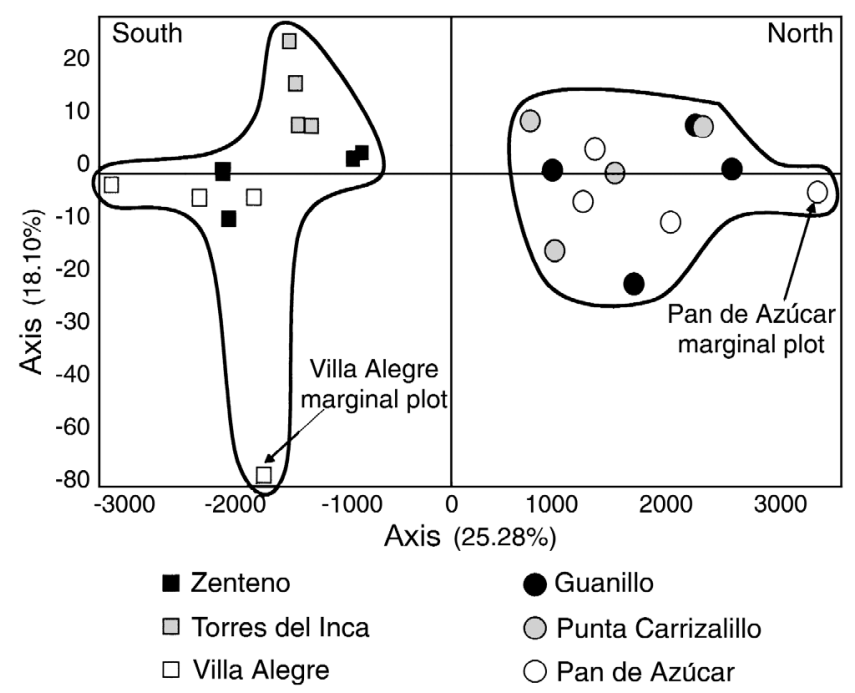

Fig. 3. Multiple correspondence analysis of the genetic diversity. Each point represents the centre of gravity of all the samples in a plot. Total variance given in parentheses 


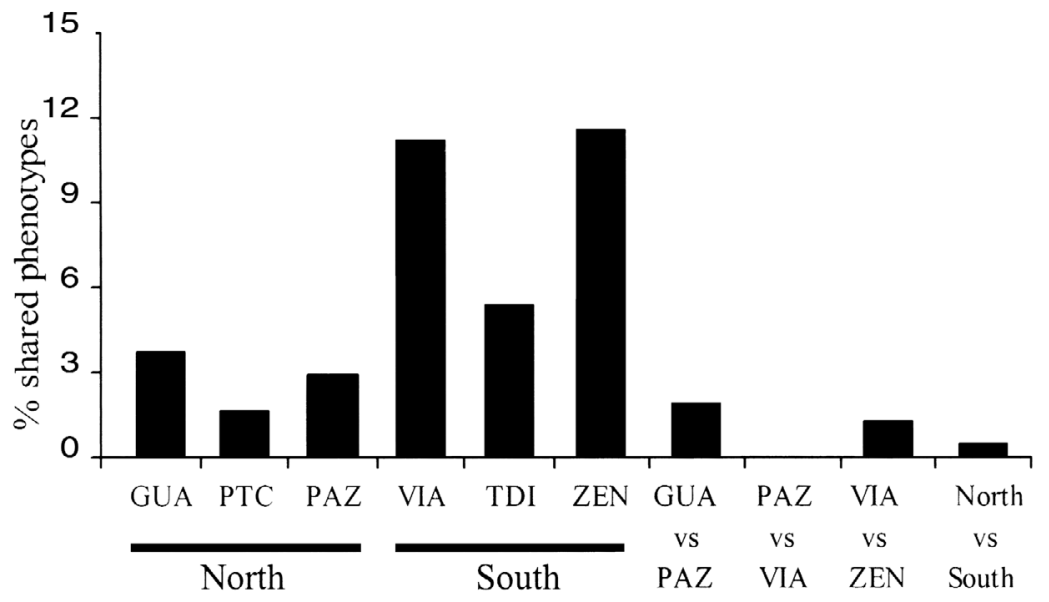

Fig. 4. Proportion of genetic phenotypes shared among localities of the northern and southern stands, and throughout the disruption area. GUA: Guanillo; PTC: Punta Carrizalillo; PAZ: Pan de Azúcar; VIA: Villa Alegre; TDI: Torres del Inca; ZEN: Zenteno

distances were not correlated to the genetic differences on these first 2 axes. Thus, whereas the first axis mainly represented the genetic structure related to the disruption, the second axis reflected the characteristics of the edge at Villa Alegre.

The analysis of shared genetic phenotypes showed that most phenotypes ( $>750)$ are unique, and less than 10 were shared by individuals from the 3 localities within each stand. The 3 localities of the northern stand shared a significantly smaller $(t=2.72, \mathrm{p}<0.05)$ proportion of phenotypes (1.7 to $3.8 \%$ of the phenotypes shared between localities) than the 3 southern localities (5.4 to $11.5 \%$ ). Although no phenotypes were shared between the 2 border localities (Fig. 4), 4 (i.e.

Table 2. Comparisons of mean pairwise $F_{\mathrm{ST}}$ between localities within stands, between stands and within versus between stands. p-values of the comparison of the mean pairwise $F_{\mathrm{ST}}$ were obtained from 2-tailed $t$-tests. Gua: Guanillo, PC: Punta Carrizalillo, PA: Pan de Azúcar, VA: Villa Alegre, TI: Torres del Inca, Zent: Zenteno

\begin{tabular}{|llllrr|}
\hline & $\begin{array}{l}\text { Pairwise } \\
\text { localities }\end{array}$ & Mean $F_{\mathrm{ST}}$ & $\begin{array}{l}\text { Pairwise } \\
\text { localities }\end{array}$ & Mean $F_{\mathrm{ST}}$ & $\mathrm{p}$ \\
\hline Within- & Zent-VA & 0.223 & Zent-TI & 0.144 & $<0.0001$ \\
stands & Gua-PA & 0.152 & Gua-PC & 0.147 & 0.547 \\
Between- & VA-PA & 0.285 & TI-PC & 0.178 & $<0.0001$ \\
stands & VA-PA & 0.285 & Gua-Zent & 0.209 & $<0.0001$ \\
& TI-PC & 0.178 & Zent-Gua & 0.207 & 0.032 \\
Between- vs. & VA-PA & 0.285 & Zent-VA & 0.223 & $<0.0001$ \\
Within-stands & VA-PA & 0.285 & Gua-PA & 0.152 & $<0.0001$ \\
& VA-PA & 0.285 & Zent-TI & 0.144 & $<0.0001$ \\
& VA-PA & 0.285 & Gua-PC & 0.147 & $<0.0001$ \\
& TI-PC & 0.178 & Zent-VA & 0.223 & $<0.001$ \\
& TI-PC & 0.178 & Gua-PA & 0.152 & 0.016 \\
& TI-PC & 0.178 & Zent-TI & 0.144 & 0.015 \\
& TI-PC & 0.178 & Gua-PC & 0.147 & 0.016 \\
\hline
\end{tabular}

$0.46 \%$ of all pairs of phenotypes) were shared between the northern and southern stands, all belonging to the most distant localities (Fig. 4). Finally, 4 phenotypes (i.e. $1.3 \%$ of the possible pairs of phenotypes) were shared between Zenteno and Villa Alegre, and 6 phenotypes (i.e. $1.9 \%$ ) were shared between Pan de Azúcar and Guanillo, both pairs of localities separated by geographic distances similar to those between the 2 border localities.

Pairwise $F_{\text {ST }}$ estimates showed a strong genetic differentiation between quadrants of Lessonia nigrescens at all spatial scales. After Bonferroni correction (nominal level of $\mathrm{p}=0.000045$ ), only 165 paired $F_{\mathrm{ST}}$, out of the 1128 comparisons, were non-significant (data matrix not shown but available upon request). However, 12 out of 24 pairwise $F_{\mathrm{ST}}$ at the smallest spatial scale (i.e. quadrants separated by $20 \mathrm{~m}$ within a plot) were not significant ( $\mathrm{p}>0.05)$. On the other hand, 4 of the significantly differentiated pairs of quadrants were from Villa Alegre. Within-locality, the mean pairwise $F_{\mathrm{ST}}$ (including spatial scales from $20 \mathrm{~m}$ to $1 \mathrm{~km}$ ) was around 0.17, except for Villa Allegre, where it reached 0.30, and for Zenteno, where it was 0.12. Comparisons of mean pairwise $F_{\mathrm{ST}}$ between localities of the same stand showed no significant differences for the northern stand $(\mathrm{p}=0.547)$ but higher differentiation between Zenteno and Villa Alegre (mean $F_{\mathrm{ST}}=0.223$ ) than between Zenteno and Torres del Inca $\left(F_{\mathrm{ST}}=0.144, \mathrm{p}<\right.$ 0.0001, Table 2). Comparisons between localities between stands showed that the differentiation between the 2 populations at the border of the disruption (i.e. Pan de Azúcar and Villa Alegre; mean $\left.F_{\mathrm{ST}}=0.285\right)$ was stronger (p $<0.0001)$ than between Punta Carrizalillo and Torres del Inca (mean $F_{\mathrm{ST}}=0.178$ ) and between Guanillo and Zenteno (mean $F_{\mathrm{ST}}=0.209$ ). Differentiation between Guanillo and Zenteno was slightly but significantly higher (p $=0.032$ ) than between Punta Carrizalillo and Torres del Inca (Table 2). Genetic differentiation was on average higher between than within stands, except when Villa Alegre was considered for the within-stand comparisons and not between stand (Table 2).

The $\Phi_{\mathrm{ST}}$ estimate from the AMOVA including all the localities from both stands revealed strong and significant overall genetic structure $\left(\Phi_{\mathrm{ST}}=0.13\right.$, $\mathrm{p}<0.001)$. The subsequent hierarchical 
Table 3. Lessonia nigrescens. Hierarchical AMOVA. ${ }^{*} \mathrm{p}<0.05 ;{ }^{* * *} \mathrm{p}<0.001 ;{ }^{\text {ns}}$ : not significant. $\Phi_{\mathrm{ST}}$ : global sub-structure index; $\Phi_{\mathrm{SC}}$ : differentiation between sub-groups within groups; $\Phi_{\mathrm{CT}}$ : differentiation between groups

\begin{tabular}{|c|c|c|c|c|c|}
\hline & & df & SS & $\%$ variation & Fixation indices \\
\hline \multicolumn{6}{|c|}{ (A) Analysis among localities and between stands } \\
\hline & Between stands & 1 & 180.7 & 7.59 & $\Phi_{\mathrm{CT}}=0.076^{* * *}$ \\
\hline & $\begin{array}{l}\text { Among localities } \\
\text { within stands }\end{array}$ & 4 & 148.7 & 5.38 & $\Phi_{\mathrm{SC}}=0.058^{* * *}$ \\
\hline & Within localities & 860 & 3248.4 & 87.03 & \\
\hline & Total & 865 & 3577.8 & & $\Phi_{\mathrm{ST}}=0.130^{* * *}$ \\
\hline \multicolumn{6}{|c|}{ (B) Analysis among localities and between sites within localities of the same stand } \\
\hline \multirow{4}{*}{ Northern Stand } & Among localities & 3 & 65.7 & 2.41 & $\Phi_{\mathrm{CT}}=0.024^{*}$ \\
\hline & $\begin{array}{l}\text { Between sites } \\
\text { within localities }\end{array}$ & 2 & 57.5 & 5.29 & $\Phi_{\mathrm{SC}}=0.054^{* * *}$ \\
\hline & Within sites & 420 & 1589.2 & 92.30 & \\
\hline & Total & 425 & 1712.3 & & $\Phi_{\mathrm{ST}}=0.077^{* * *}$ \\
\hline \multirow[t]{4}{*}{ Southern Stand } & Among localities & 3 & 82.9 & 3.08 & $\Phi_{\mathrm{CT}}=0.031^{*}$ \\
\hline & $\begin{array}{l}\text { Between sites } \\
\text { within localities }\end{array}$ & 2 & 70.6 & 7.02 & $\Phi_{\mathrm{SC}}=0.072^{* * *}$ \\
\hline & Within sites & 420 & 1531.2 & 89.90 & \\
\hline & Total & 425 & 1684.8 & & $\Phi_{\mathrm{ST}}=0.101^{* * *}$ \\
\hline \multicolumn{6}{|c|}{ (C) Intra-locality analyses between sites and between plots within sites } \\
\hline \multirow[t]{4}{*}{ Guanillo } & Between sites & 1 & 17.3 & 1.72 & $\Phi_{\mathrm{CT}}=0.017 \mathrm{~ns}$ \\
\hline & $\begin{array}{l}\text { Between plots } \\
\text { within sites }\end{array}$ & 2 & 24.2 & 7.18 & $\Phi_{\mathrm{SC}}=0.073^{* * *}$ \\
\hline & Within plots & 129 & 447.9 & 91.10 & \\
\hline & Total & 132 & 489.4 & & $\Phi_{\mathrm{ST}}=0.089^{* * *}$ \\
\hline \multirow[t]{4}{*}{ Punta Carrizalillo } & Between sites & 1 & 11.3 & 0.97 & $\Phi_{\mathrm{CT}}=0.010^{\mathrm{ns}}$ \\
\hline & $\begin{array}{l}\text { Between plots } \\
\text { within sites }\end{array}$ & 2 & 17.4 & 4.46 & $\Phi_{\mathrm{SC}}=0.045^{* * *}$ \\
\hline & Within plots & 115 & 425.3 & 94.57 & \\
\hline & Total & 118 & 454.1 & & $\Phi_{\mathrm{ST}}=0.054^{* * *}$ \\
\hline \multirow[t]{4}{*}{ Pan de Azúcar } & Between sites & 1 & 28.8 & 3.08 & $\Phi_{\mathrm{CT}}=0.031 \mathrm{~ns}$ \\
\hline & $\begin{array}{l}\text { Between plots } \\
\text { within sites }\end{array}$ & 2 & 33.5 & 7.32 & $\Phi_{\mathrm{SC}}=0.075^{* * *}$ \\
\hline & Within plots & 170 & 640.7 & 89.61 & \\
\hline & Total & 173 & 703.1 & & $\Phi_{\mathrm{ST}}=0.104^{* * *}$ \\
\hline \multirow[t]{4}{*}{ Villa Alegre } & Between sites & 1 & 28.5 & -2.02 & $\Phi_{\mathrm{CT}}=0 \mathrm{~ns}$ \\
\hline & $\begin{array}{l}\text { Between plots } \\
\text { within sites }\end{array}$ & 2 & 65.4 & 20.05 & $\Phi_{\mathrm{SC}}=0.197^{* * *}$ \\
\hline & Within plots & 141 & 482.6 & 81.97 & \\
\hline & Total & 144 & 576.6 & & $\Phi_{\mathrm{ST}}=0.180^{* * *}$ \\
\hline \multirow[t]{4}{*}{ Torres del Inca } & Between sites & 1 & 13.9 & 1.67 & $\Phi_{\mathrm{CT}}=0.017^{\mathrm{ns}}$ \\
\hline & Between plots & 2 & 18.9 & 5.32 & $\Phi_{\mathrm{SC}}=0.054^{* * *}$ \\
\hline & Within sites & & 1278 & 0201 & \\
\hline & $\begin{array}{l}\text { within plots } \\
\text { Total }\end{array}$ & $\begin{array}{l}126 \\
129\end{array}$ & $\begin{array}{l}427.8 \\
460.6\end{array}$ & 93.01 & $\Phi_{\mathrm{ST}}=0.070^{* * *}$ \\
\hline \multirow[t]{4}{*}{ Zenteno } & Between sites & 1 & 28.1 & 5.90 & $\Phi_{\mathrm{CT}}=0.059^{* * *}$ \\
\hline & $\begin{array}{l}\text { Between plots } \\
\text { within sites }\end{array}$ & 2 & 22.0 & 5.29 & $\Phi_{\mathrm{CT}}=0.056^{* * *}$ \\
\hline & Within plots & 161 & 514.5 & 88.81 & \\
\hline & Total & 164 & 564.6 & & $\Phi_{\mathrm{ST}}=0.112^{* * *}$ \\
\hline
\end{tabular}

analysis revealed that the genetic differentiation between the northern and southern stands was higher $\left(\Phi_{\mathrm{CT}}=0.076\right)$ than the genetic differentiation among localities within each stand $\left.\Phi_{\mathrm{SC}}=0.058\right)$, although both were highly significant ( $p<0.001$, Table $3 \mathrm{~A})$. The hierarchical analysis within each stand confirmed a highly significant genetic structure $\left(\Phi_{\mathrm{ST}}=0.077\right.$ in the north, $\Phi_{\mathrm{ST}}=0.101$ in the south, $\mathrm{p}<0.001$ for both), but revealed that genetic differentiation among localities was weaker than between sites within localities (Table 3B). A similar trend was revealed by the hierarchical analyses at the within-locality scale: the highly significant genetic structure $(p<0.001$ in all 6 cases) was mainly due to a highly significant genetic differentiation between plots within sites, whereas $\Phi_{\mathrm{CT}}$ were always smaller than $\Phi_{\mathrm{SC}}$ and significant in only 1 case 
(Zenteno, Table 3C). In all the intra-locality analyses, 94.9 to $100 \%$ of the total genetic variance was concentrated at the smallest spatial scales (within plots and between plots within sites, Table 3C).

\section{DISCUSSION}

This study tested the hypothesis of a reduced gene flow between populations of the kelp Lessonia nigrescens due to habitat disruption by analyzing the genetic variability across a human-induced interruption in the distribution of the species. The population genetic structure within continuous stands was first analyzed to understand the patterns of genetic variability in the absence of a disrupting factor. In the light of these interpretations, the pattern of genetic differentiation across the interruption of species distribution is discussed in order to understand the role of the human induced disruption.

\section{Population genetic structure within continuous stands}

We observed strong genetic structure within stands of Lessonia nigrescens, indicating that the localities are strongly genetically differentiated. The pattern was not hierarchical, however, i.e. genetic structure was always stronger at the smallest spatial scales regardless of the spatial units taken into consideration, and no isolation by distance was detected. This was indicated by the within-stand AMOVAs that always showed a strong overall structure, but differentiation among sub-groups within groups was always higher than differentiation among groups. Further support came from the MCA, which did not show any grouping of plots according to their geographical origin (except for plots in Torres del Inca on the first axis), indicating that populations are at migration-drift disequilibrium (Slatkin 1993). This has already been reported for the green algae Cladophoropsis membranacea, where genetic differentiation among populations was stronger within than among islands of the Canary archipelago (van der Strate et al. 2003). These authors argued that historical events such as paleoclimatic changes since the last glaciation period may explain the observed pattern rather than the potential gene flow among populations. In the case of L. nigrescens, historical changes cannot explain the observed genetic structure because the disequilibrium pattern was also detected at the smallest spatial scales.

A possibile explaination for the genetic sub-structure observed in Lessonia nigrescens is that, at small spatial scales, genotypes are not randomly distributed but are organized in families (i.e. groups of genetically related individuals), as a result of the restricted dispersal of meiospores and/or of male gametes and recruitment taking place near the parental individual. Short dispersal distance is common in algae (Santelices 1990, Destombe et al. 1992, Norton 1992) and is generally associated with strong genetic structure at scales of up to a few tens of meters (Kusumo \& Druehl 2000, Wright et al. 2000, Faugeron et al. 2001, Zucarello et al. 2001, van der Strate et al. 2003). An example of this comes from the paternity analyses of Gracilaria gracilis (Engel et al. 1999), where $80 \%$ of fertilizations reportedly occurred at distances smaller than $1 \mathrm{~m}$ (i.e. within tide pools) and resulted in a pattern of genetic structure determined by the spatial distribution of the tide pools (Engel et al. 2004). The apparent absence of isolation by distance, however, suggests that some long distance dispersion occurs among populations of $L$. nigrescens.

To fully understand the biological basis of these results, we must take into consideration the complex life cycle of kelps. Lessonia nigrescens is a dioecious organism with male and female organs developing on different microscopic haploid individuals. As in other Laminariales, the encounter of the egg with the spermatia in L. nigrescens is likely under the control of pheromones (Lüning \& Müller 1978). Fertilization occurs on the female gametophyte only a few hours after release and therefore a successful fertilization requires that male and female gametophytes recruit at short distances from each other (i.e. a few centimeters) and become mature simultaneously because of the short life span of spermatia and the pheromone signals needed to find the female plant. The descendent diploid sporophyte does not disperse but germinates and develops in situ. Furthermore, meiospores are produced at the end of sporophytic blades and are released into the water column. Their life span as well as the duration of their capacity to adhere to the substratum is apparently short (less than $24 \mathrm{~h}$, E.A. Martínez. unpubl. data), although their potential for long distance dispersal, either as free-living spores or on drifting fragments of mature thallus, is unknown and therefore should not be underestimated. Altogether, dispersal of spores and recruitment of juveniles of $L$. nigrescens seem to be limited by a series of factors (Martínez \& Santelices 1998), suggesting that most events of recruitment occur in the vicinity of a parental individual, inducing a patchy structure and thus a high level of intra-site genetic structure. On the other hand, episodic events of longer distance dispersion that prevent isolation by distance cannot be ruled out and provide an alternative explanation for shared genotypes and absence of isolation by distance within the scale of $40 \mathrm{~km}$. This pattern has been described in 
the plant Silene dioica, where migration seems to be restricted as gravity is the major factor in the dispersion of seeds. In this case, differentiation among subgroups was twice as high as differentiation among groups (Giles et al. 1998), a pattern due to the kinstructured populations of small patches of genetically related individuals (Ingvarsson \& Giles 1999). In order to refine our understanding of the small scale patterns occurring within populations of L. nigrescens, such as inbreeding and relatedness, a new study based on codominant markers would be required.

\section{Genetic differentiation due to habitat disruption}

Our study demonstrates that the interruption of the continuous distribution of Lessonia nigrescens due to the disruption of the habitat in the Chañaral area coincides with an increased genetic differentiation between stands occurring northward and southward from the impacted area. Three lines of evidence support this view. First, the MCA revealed a clear separation of the northern and southern stands based on the patterns of genetic variance among plots. Second, the proportion of genetic phenotypes shared by individuals across the disruption is reduced in comparison with the proportion of shared phenotypes between populations within stands. Indeed, only $0.5 \%$ of the phenotypes were shared across the disruption. Furthermore, they were shared by individuals from Guanillo and Zenteno, the 2 most distant localities, and may be likely due to homoplasy of the RAPD markers or to historical gene flow between these localities before the disruption. When considering similar spatial distances, results showed that not a single phenotype was shared between the 2 localities at the border of the disruption, whereas 1.9 and $1.3 \%$ of the phenotypes were shared between border populations and Guanillo or Zenteno, respectively. This conclusion must be viewed with caution, however, because of the low overall number of phenotypes that are shared among localities (probably due to genetic differentiation). The third line of evidence comes from the genetic differentiation estimates obtained from the comparisons of mean pairwise $F_{\mathrm{ST}}$ and from the AMOVA when comparisons between and within stands were included in the same analyses. In this case, stronger genetic differentiation was observed across the disruption than within each stand, even though geographic distances of the compared localities were, in both cases, similar (in the AMOVA). Villa Alegre showed the strongest genetic differentiation, indicating a strong border effect on the genetic composition of this population.

The singularity of Villa Alegre introduces some degree of uncertainty when assigning a disruptive effect on gene flow to the area of disruption caused by the mining wastes. Indeed, $F_{\mathrm{ST}}$ estimates may be the result of a founding event having occurred recently in this population, reducing the genetic diversity and increasing its genetic differentiation (see next section), rather than a reduced gene flow between stands due to the disruption. By comparing the mean differentiation between Torres del Inca and Punta Carrizalillo with the mean differentiation between Guanillo and Punta Carrizalillo or between Zenteno and Torres del Inca, we find that genetic differentiation is roughly associated with the geographic distances between pairs of populations: mean $F_{\mathrm{ST}} \approx 0.145$ for 25 to $30 \mathrm{~km}$ between Guanillo and Punta Carizalillo and between Zenteno and Torres del Inca; $F_{\mathrm{ST}}=0.178$ for $60 \mathrm{~km}$ between Punta Carizalillo and Torres del Inca; mean $F_{\mathrm{ST}} \approx 0.207$ for $120 \mathrm{~km}$ between Guanillo and Zenteno. These results suggest that genetic differentiation between the most distant localities is the result of a historical pattern which may have been unmodified by the disruption of the habitat in the area around Chañaral. Not only was the genetic differentiation strong between the border localities, the genetic structure was stronger between stands than within stands, even when Villa Alegre was included in the analysis. Overall, and despite the uncertainty generated by the strong genetic differentiation of Villa Alegre, these results indicate that the interruption of the continuous distribution of the species due to habitat disruption, which lasted more than $60 \mathrm{yr}$, was accompanied by a reduction of gene flow of a magnitude and duration sufficient to allow genetic differentiation between stands to occur.

The existence of barriers to gene flow has been reported for several marine organisms (Johnson \& Black 1995, Ruckelshaus 1998, Bernardi 2000, Riginos \& Nachman 2001), including algae (Faugeron et al. 2001, Billot et al. 2003). All these studies represent examples of natural barriers that have been present for a much longer time, however, and therefore have affected a much higher number of generations of the species under study. In our case, however, only a few generations have passed since the disruption started (60 generations at most, assuming 1 generation per year, which is probably the shortest estimation for Lessonia nigrescens). To our knowledge, this is the first report describing the effect of habitat disruption, and the resulting interruption of a species distribution, on the genetic structure and gene flow in a marine organism. However, reports on terrestial organisms have revealed that habitat fragmentation has strong effects on the genetic diversity and population differentiation (see Knutsen et al. 2000, Caizergues et al. 2003, Murren 2003 and Williams et al. 2003 for some of the most recent studies). A major conse- 
quence of habitat disruption and fragmentation is its effect on the migration rates among populations. Habitat fragmentation creates new barriers, regardless of the dispersal capacity of a species, that reduce the chances for a propagule to recruit in a suitable habitat. Higgins et al. (2003) showed that the migration rate of a species is easily overestimated under habitat loss because most of the mating and most of the recruitment occur at a shorter distance than is allowed by the dispersal potential of the species. Furthermore, reproductive output may be reduced in fragmented plant populations, probably due to increased pollen limitation, as has been shown in the marine seagrass Zostera marina (Reusch 2003). In the case of L. nigrescens, which apparently disperses at short distances (but see Reed et al. 1988), the effect of habitat disruption over more than $40 \mathrm{~km}$ is likely to prevent the recruitment of spores coming from the opposite side of the disruption, reducing the realized migration rate across the impacted area to zero.

\section{Recolonization or permanent limit at the border of the disruption?}

The populations at the border of the stands in Villa Alegre and Pan de Azúcar were of particular interest as they were expected to exhibit distinct patterns, such as a reduced density and/or a lower level of genetic diversity. Pan de Azúcar (edge of the northern stand) was lower in density than its neighbor Punta Carrizalillo, but no difference was observed for Guanillo. The low density of Lessonia nigrescens in Guanillo was, however, probably caused by heavy harvesting taking place in the area at the moment of sampling, which reduces the potential differences between border and control populations. Pan de Azúcar did not show a reduced genetic diversity nor an increased substructure or genetic differentiation as compared with the other populations of the northern stand. In fact, the highest values of genetic diversity were found in this locality, as well as some of the lowest proportions of shared genotypes.

On the other hand, Villa Alegre, which is at the edge of the southern stand, showed a reduced density, a slightly reduced proportion of polymorphic loci (although the difference was not statistically significant) and a higher proportion of phenotypes shared by 2 or more individuals. The most striking feature of Villa Allegre was its strong genetic differentiation from all the other populations, and the strength of the within-locality genetic sub-structuring. Furthermore, MCA clearly differentiated its most peripheral plot. These results may be an indication that this population was established recently and had experi- enced some founder effect. It further suggests that recolonization is occurring northward. The detection of some signals of a recent foundation raises the question of whether a recolonisation process in the impacted area is really taking place. Alternatively, it could be suggested that the observed patterns were the result of a stochastic process of repeated foundation and extinction events affecting the populations at this edge of the disruption. A fluctuating influence of the heavy metal pollution at the edges of the impacted area may explain such a stochastic process. We should also take into account, however, that the composition of the mining wastes has recently changed. Indeed, initial discharges from the mine brought dissolved copper and particulate sandy tailings into the coast, a situation that changed in 1990 when only 'clear' waters (wastes without tailings) started to be released. The question of why Lessonia nigrescens remains absent from the impacted area and its surroundings, considering the new conditions, is still open. There are 2 main hypotheses to explain this absence. The first is that $L$. nigrescens disperses at such short distances that the recolonisation process is very slow. This hypothesis is, at the least, controversial. Indeed, in one case after massive and extensive mortality of $L$. nigrescens during the strong El Niño event of 1982-1983, L. nigrescens recolonized, in $20 \mathrm{yr}$, more than $50 \mathrm{~km}$ (Martínez et al. 2003). In the case of the human-induced disruption around Chañaral, the breach between the northern and the southern stand is almost $40 \mathrm{~km}$ and it has remained open for $60 \mathrm{yr}$. The second hypothesis is that $L$. nigrescens cannot recolonize because the habitat is still not suitable. Simultaneous studies indicate that $L$. nigrescens is sensitive to copper contamination, as suggested by the inefficient physiological responses to oxidative stress expressed in individuals transplanted into the impacted sites and by the negative effect of copper-enriched seawater of the impacted area on spore settlement and germination (J. A. Correa unpubl. data). These results suggest that, although dispersion and recruitment of meiospores is possible, survival and sexual maturation of microscopic gametophytes and macroscopic sporophytes can be strongly limited in impacted areas, severely reducing the possibility of recolonization. Thus, recolonization is probably not occurring, except sporadically, in Villa Alegre, where the effects of pollution may have ceased.

In conclusion, we have shown that Lessonia nigrescens populations exhibit a highly genetic structure at small geographic scales, probably induced by short distance dispersal of spores and/or gametes. Our study confirms the fact that continuous kelp beds are affected by habitat fragmentation (Billot et al. 2003) 
and for the first time stresses the role of humaninduced disruption on the genetic connectivity of seaweed populations.

Acknowledgements. Help from A. Silva and G. Rodriguez with field sampling and laboratory work greatly improved the efficiency of this study. We are also deeply in debt to C. Camus, L. Contreras, C. Henriquez, C. Lopez and G. Parada for their help with field sampling. Special recognition is given to 2 anonymous reviewers who contributed significantly to an improvement of the original version of the manuscript. Funding was provided by grants FONDAP-FONDECYT 15010001, ECOS-CONICYT C02B02 and IAI-SGP 024. S.F. was supported by grant INCO-DEV ICA4-CT-2001-10021.

\section{LITTERATURE CITED}

Belkir K, Borsa P, Goudet J, Chiki L, Bonhomme F (1996) Genetix, Logiciel sous Windows ${ }^{\mathrm{TM}}$ pour la génétique des populations. Laboratoire Génome, Populations, Interactions. CNRS UMR 5000. Université Montpellier II, Montpellier

Bernardi G (2000) Barriers to gene flow in Embiotica jacksoni, a marine fish lacking pelagic larval stage. Evolution 54:226-237

Billot C, Engel CR, Rousvoal S, Kloareg B, Valero M (2003) Current patterns, habitat discontinuities and populations gentic structure: the case of the kelp Laminaria digitata in the English Channel. Mar Ecol Prog Ser 253:111-121

Bohonak AJ (1999) Dispersal, gene flow, and population structure. Q Rev Biol 74:21-45

Bussell JD (1999) The distribution of random amplified polymorphic DNA (RAPD) diversity amongst populations of Isotoma petraea (Lobeliaceae). Mol Ecol 8:775-789

Caizergues A, Rätti O, Helle P, Rotelli L, Ellison L, Rasplus J Y (2003) Population genetic structure of male black grouse (Tetrao tetrix L.) in fragmented vs. continuous landscapes. Mol Ecol 12:2297-2305

Cancino J, Santelices B (1981) The ecological importance of kelp-like holdfasts as habitat of invertebrates in Central Chile. II. Factors affecting community organization. Proc Int Seaweed Symp 10:241-246

Castilla JC, Nealler E (1978) Marine environmental impact due to mining activities of El Salvador copper mine, Chile. Mar Pollut Bull 9:67-70

Correa JA, Castilla JC, Ramírez M, Varas M and 5 others Copper, copper mining tailing and their effects on marine algae in northern Chile. J Appl Phycol 11:57-67

Destombe C, Godin J, Lefebvre C, Dehorter O, Vernet P (1992) Differences in dispersal abilities of haploid and diploid spores of Gracilaria verrucosa (Gracilariales, Rhodophyta). Bot Mar 35:93-98

Engel C, Wattier R, Destombe C, Valero M (1999) Performance of non-motile male gametes in the sea: analysis of paternity and fertilization success in a natural population of a red seaweed, Gracilaria gracilis. Proc R Soc Lond B 166:1879-1886

Engel CR, Destombe C, Valero M (2004) Mating system and gene flow in the red seaweed Gracilaria gracilis: effects of haploid-diploid life history and intertidal rocky shore landscape on fine-scale genetic structure. Heredity 92:289-298

Excoffier L, Smouse PE, Quattro JM (1992) Analysis of molecular variance inferred from metric distances among DNA haplotypes: application to human mitochondrial DNA restriction data. Genetics 131:479-491

Faugeron S (2002) Epidemiology, biologie et génétique des populations de Mazzaella laminarioides (Rhodophyta) infectée par Endophyton ramosum (Chlorophyta) et par Pleurocapsa sp. (Cyanobactérie). PhD thesis, Université Lille I, Lille

Faugeron S, Valero M, Destombe C, Martin EA, Correa JA (2001) Hierarchical spatial structure and discriminant analysis of genetic diversity in the red alga Mazzaella laminarioides (Gigartinales, Rhodophyta). J Phycol 37: $705-716$

Giles BE, Lundqvist E, Goudet J (1998) Restricted gene flow and subpopulation differentiation in Silene dioica. Heredity $80: 715-723$

Guinand B (1996) Use of multivariate model using allele frequency distributions to analyse patterns of genetic differentiation among populations. Biol J Linn Soc 58:173-195

Hanski I, Gilpin ME (eds) (1997) Metapopulation biology. Ecology, genetics and evolution. Academic Press, San Diego, CA

Higgins SI, Lavorel S, Revilla E (2003) Estimating plant migration rates under habitat loss and fragmentation. Oikos 101:354-366

Ingvarsson PK, Giles BE (1999) Kin-structured colonization and small-scale genetic differentiation in Silene dioica. Evolution 53:605-611

Johnson MS, Black R (1995) Neighbourhood size and the importance of barriers to gene flow in an intertidal snail. Heredity 75:142-154

Jones CG, Lawton JH, Shachak M (1994) Organisms as ecosystem engineers. Oikos 69:373-86

Knutsen K, Rukke BA, Jorde PE, Ims RA (2000) Genetic differentiation among populations of the beetle Bolitophagus reticulatus (Coleoptera: Tenebrionidae) in a fragmented and a continuous landscape. Heredity 84:667-676

Kusumo HT, Druehl LD (2000) Variability over space and time in the genetic structure of the winged kelp Alaria marginata. Mar Biol 136:397-409

Lüning K, Müller DG (1978) Chemical interaction in sexual reproduction of several Laminariales: release and attraction of spermatozoids. Z Pflanzenphysiol 89:33-41

Manel S, Shwartz MK, Luikart G, Tarbelet P (2003) Landscape genetics: combining landscape ecology and population genetics. Trends Ecol Evol 18:189-197

Martínez EA, Santelices B (1998) Selective mortality on haploid and dilpoid microscopic stages of Lessonia nigrescens Bory (Phaeophyta, Laminariales). J Exp Mar Biol Ecol 229:219-239

Martínez EA, Cardenas L, Pinto R (2003) Recovery and genetic diversity of the intertidal kelp Lessonia nigrescens (Phaeophyceae) 20 years after El Niño 1982/83. J Phycol 39:504-508

Muñoz M, Santelices B (1989) Determination of the distribution and abundance of the limpet Scurria scurra on the stipes of the kelp Lessonia nigrescens in Central Chile. Mar Ecol Prog Ser 54:277-285

Murren CJ (2003) Spatial and demographic population genetic structure in Catasetum viridiflavum across a human-disturbed habitat. J Evol Biol 16:333-342

Norton TA (1992) Dispersal by macroalgae. Br Phycol J 27:293-301

Palumbi S (1994) Genetic divergence, reproductive isolation and marine speciation. Annu Rev Ecol Syst 25:547-572

Reed D, Laur D, Ebeling A (1988) Variation in algal dispersal and recruitment: the importance of episodic events. Ecol Monogr 58:321-335 
Reusch TBH (2003) Floral neighborhoods in the sea: How floral density, opportunity for outcrossing and population fragmentation affect seed set in Zostera marina. J Ecol 91:610-615

Rice WR (1990) A consensus combined $P$-value test and the family-wide significance of component tests. Biometrics 46:303-308

Riginos C, Nachman MW (2001) Population subdivision in marine environments: the contributions of biogeography, geographical distance and discontinuous habitat to genetic differentiation in a blennioid fish, Axoclinus nigricaudus. Mol Ecol 10:1439-1453

Ruckelshaus MH (1998) Spatial scale of genetic structure and an indirect estimate of gene flow in eelgrass Zostera marina. Evolution 52:330-343

Santelices B (1990) Patterns of reproduction, dispersal and recruitment in seaweeds. Oceanogr Mar Biol Annu Rev 28:177-276

Santelices B, Ojeda P (1984) Recruitment, growth and survival of Lessonia nigrescens (Phaeophyta) at various tidal levels in exposed habitats of central Chile. Mar Ecol Prog Ser 19:73-82

Santelices B, Castilla JC, Cancino J, Schmiede P (1980) Comparative ecology of Lessonia nigrescens and Durvillaea antartica (Phaeophyta) in central Chile. Mar Biol 59:119-132

Saunders DA, Hobbs RJ, Margules CR (1991) Biological consequences of ecosystem fragmentation: a review. Conserv Biol 5:18-32

Schneider S, Roseli D, Excoffier L (eds) (2000) Arlequin ver. 2.000: a software for population genetics data analysis. Genetics and Biometry Laboratory, University of Geneva, Geneva

She J X, Autem M, Kotoulas G, Pasteur N, Bonhomme F (1987) Multivariate analysis of genetic exchanges between Solea aegyptiaca and Solea senegalensis (Teleosts,

Editorial responsibility: Otto Kinne (Editor-in-Chief), Oldendorf/Luhe, Germany
Soleidae). Biol J Linn Soc 32:357-371

Slatkin M (1993) Isolation by distance in equilibrium and nonequilibrium populations. Evolution 47:263-279

Sork VL, Nason J, Campbell DR, Fernandez JF (1999) Landscape approaches to historical and contemporary gene flow in plants. Trends Ecol Evol 14:219-224

Valero M, Engel C, Billot C, Kloareg B, Destombe C (2001) Concepts and issues of population genetics in seaweeds. Cah Biol Mar 42:53-62

van der Strate H, van de Zande L, Stam WT, Haroun RJ, Olsen JL (2003) Within-island differentiation and betweenisland homogeneity: non-equilibrium population structure in the seaweed Cladophoropsis membranaceae (Chlorophyta) in the Canary Islands. Eur J Phycol 38:15-23

Vásquez J, Santelices B (1984) Comunidades de macro-invertebrados en discos de Lessonia nigrescens Bory (Phaeophyta) en Chile central. Rev Chil Hist Nat 57:131-154

Vásquez JA, Camus P, Ojeda FP (1998) Diversidad, estructura y funcionamiento de ecosistemas costeros rocosos del norte de Chile. Rev Chil Hist Nat 71:479-499

Villouta E, Santelices B (1984) Comunidades submareales de Lessonia en Chile Central. Rev Chil Hist Nat 58:131-154

Williams BL, Brawn JD, Paige KN (2003) Landscape scale genetic effects of habitat fragmentation on a high gene flow species: Speyeria idalia (Nymphalidae). Mol Ecol 12:11-20

Wright JT, Zuccarello GC, Steinberg PD (2000) Genetic structure of the subtidal red alga Delisea pulcra. Mar Biol 136:439-448

Young A, Boyle T, Brown T (1996) The population genetic consequences of habitat fragmentation for plants. Trends Ecol Evol 11:413-418

Zucarello GC, Yates PH, Wright JT, Barlett J (2001) Population structure and physiological differentiation of haplotypes of Caloglossa leprieurii (Rhodophyta) in a mangrove intertidal zone. J Phycol 37:235-244

Submitted: January 5, 2004; Accepted: October 12, 2004 Proofs received from author(s): February 24, 2005 